\title{
Model reactions of calixarenes and their esterified derivatives with glycidyl phenyl ether for thermal curing reactions of epoxy resins
}

\author{
Shengang $\mathrm{Xu}^{1}$, Hiroto Kudo ${ }^{1}$, Tadatomi Nishikubo ${ }^{1}$, Shinya Nakamura ${ }^{2}$ and Shunichi Numata ${ }^{2}$ \\ Calixarenes (CAs) are perfectly defined cyclic phenolic oligomers with potential applications as curing agents for polyfunctional \\ epoxy resins to prepare cured epoxy resins with high glass transition temperature and high thermal stability. This paper explores \\ the reaction mechanisms and optimal reaction conditions of CAs with epoxy groups by studying the model reactions of \\ calix[4]resorcinarene (CRA), $p$-tert-butylcalix[n]arene (BCA[n], $n=4,6,8)$ and their esterified derivatives with glycidyl phenyl \\ ether (GPE). For reactions of completely esterified CRA with GPE, the optimum reaction conditions were determined as \\ tetraphenylphosphonium chloride catalyst in chlorobenzene at $120^{\circ} \mathrm{C}$ for $6 \mathrm{~h}$. Under the above reaction conditions, the degree \\ of introduction of GPE (D.I.) to CRA and its esterified derivatives was greater than $95 \%$, whereas D.I.s were lower than $81 \%$ for \\ $\operatorname{BCA}[n](n=4,6,8)$ and their esterified derivatives. This difference in reactivity resulted from the difference in intermolecular \\ hydrogen bonding and steric hindrance between CAs. These results indicate that CRA and its derivatives have great potential \\ as curing agents for polyfunctional epoxy resins.
}

Polymer Journal (2010) 42, 456-463; doi:10.1038/pj.2010.34

Keywords: calixarene; epoxy resin; glycidyl phenyl ether; model reaction

\section{INTRODUCTION}

Calixarenes (CAs) are a class of macrocycle or cyclic oligomers formed by a condensation reaction between a phenol and an aldehyde. Many studies have been published on CAs, ${ }^{1-3}$ such as their applications in enzyme mimetics, in ion-sensitive electrodes or sensors, in selective membranes, nonlinear optics, nanotechnology and in the highperformance liquid chromatography (HPLC) stationary phase, with each of these based on the strong abilities of CAs to receive ionic and neutral species.

CAs also contain many hydroxy groups in one molecule, making it easy to modify them by introducing new functional groups. Recently, Nishikubo et al. ${ }^{4-7}$ reported successful synthesis of CA derivatives containing certain polymerizable groups or protection groups such as allyl ether ${ }^{4}$ ethoxy vinyl ether, ${ }^{4}$ propargyl ether, ${ }^{4}$ oxetane, ${ }^{5}$ oxirane, ${ }^{5}$ spiro ortho ether groups ${ }^{6}$ and $t$-butyl ester groups, ${ }^{7}$ and these derivatives were used to construct high-performance photocurable oligomers or high-resolution photoresists. They also found that these substituted CA derivatives had high glass transition temperature, excellent thermal stability and good solubility in organic solvents such as $\mathrm{N}$-methyl-2-pyrrolidone, dimethylsulfoxide, dimethylacetamide and dimethyl formamide.

Epoxy resins, ${ }^{8-10}$ a class of cured materials prepared by the thermal curing reactions of polyfunctional epoxy compounds with poly-amines, -phenols, -thiols, -carboxylic acids or -carboxylic anhydrides, have been widely used in many industrial applications such as coating, painting, as an elastomer, for adhesion and in electronics. Cured epoxy resins using phenol resins ${ }^{11}$ as curing agents have been widely used as molding encapsulants for electronic devices because of their well-balanced properties such as excellent heat and chemical resistance and good mechanical and electrical properties.

Because CAs are perfectly defined cyclic phenol resins, epoxy resins cured using CA-curing agents may have a better thermal stability than epoxy resins cured using linear phenol derivatives. Furthermore, CA-cured epoxy resins could be prepared without hydroxy groups or with special functionalities by partially or completely substituting the hydroxy groups of CAs by functional groups such as ester groups, ether groups, phosphorus-containing groups and silicon-containing groups. Moreover, the properties of cured materials could be easily adjusted according to different needs by controlling the variety and content of substituent groups in CA derivatives. Previously, we confirmed that groups such as polyfunctional active ester, ${ }^{12,13}$ dicarboxylic acid and diol, ${ }^{14}$ triazine dichloride ${ }^{15}$ and triazine diaryl ether ${ }^{16}$ can react with polyfunctional epoxy resins or bis(epoxide)s using quaternary onium salts or crown ether salt complexes as catalysts to form high-performance thermosetting resins or linear polymers. However, after these functional groups were introduced into CAs, it

${ }^{1}$ Faculty of Engineering, Department of Material and Life Chemistry, Kanagawa University, Rokkakubashi, Kanagawa-ku, Yokohama, Japan and ${ }^{2}$ High Performance Material R\&D Center, Hitachi Chemical Co. Ltd, Hitachi-shi Ibaraki, Japan

Correspondence: Professor T Nishikubo, Department of Material and Life Chemistry, Kanagawa University, 3-27-1, rokkakubashi, Kanagawa-ku, Yokohama 221-8686, Japan. E-mail: nishikubot@kanagawa-u.ac.jp

Received 25 January 2010; revised 12 March 2010; accepted 18 March 2010 
was unclear whether the substituted CAs had sufficient reactivity to cure epoxy resins and what the curing reaction mechanisms were.

In this article, we studied the model reactions of some CAs and their esterified derivatives with a monofunctional epoxy compound (glycidyl phenyl ether, GPE). Completely esterified calix[4]resorcinarene (CRA) was reacted with GPE to optimize reaction conditions such as catalyst, solvent, temperature and time. Those optimized reaction conditions were then used to investigate the influences of the degree of esterification (D.E.) of CA derivatives and CA type on the reactivity of CAs with GPE.

\section{EXPERIMENTAL PROCEDURE}

\section{Materials}

Calix [4]resorcinarene and $p$-tert-butylcalix[n]arene (BCA[n], $n=4,6,8)$ were kindly donated by Japanese chemical companies such as Sanbo Chemical Co. (Sakai-shi, Osaka, Japan) Hitachi Chemical Co. (Hitachi-shi, Ibaraki, Japan), Sugai Chemical Co. (Wakayama-shi, Wakayama, Japan) and Shin Nakamura Chemical Industry Co. (Wakayama-shi, Wakayama, Japan) Glycidyl phenyl ether, chlorobenzene, triphenylphosphine, 4-dimethyl aminopyridine, tetrabutylphosphonium bromide, tetraphenylphosphonium bromide and tetraphenylphosphonium chloride (TPPC) were purchased from Tokyo Kasei (Chuo-ku, Tokyo, Japan), Aldrich (St Louis, MO, USA), Kanto (Chuo-ku, Tokyo, Japan) and Wako Chemical Industry Co. Ltd (Chuo-ku, Osaka, Japan), respectively, and used without further purification. All other reagents and solvents were used as received.

\section{Measurements}

Infrared (IR) absorption spectra were measured on a Jasco FT/IR-420 spectrometer (Jasco, Hachioji-shi, Tokyo, Japan). ${ }^{1} \mathrm{H}$ nuclear magnetic resonance (NMR) spectra were recorded on JEOL JNM-a-600 (JEOL, Akishima-shi, Tokyo, Japan) with $\mathrm{Me}_{4} \mathrm{Si}$ (tetramethylsilane) as an internal standard. Number-average molecular weight $\left(M_{\mathrm{n}}\right)$ and molecular weight distribution $\left(M_{\mathrm{w}} /\right.$ $M_{\mathrm{n}}$ ) values were estimated by size exclusion chromatography with a Tosoh HPLC HLC-8020 system (Tosoh, Minato-Ku, Tokyo, Japan) using tetrahydrofuran as the eluent and polystyrene as a standard at $40^{\circ} \mathrm{C}$. Reaction products were isolated by a recycling preparative HPLC (model HPLC-908 liquid chromatography; Japan Analytical Industry Co. Ltd, Nishitama, Tokyo, Japan) connected to JAIGEL-1H-AF and JAIGEL-1H-A columns using chloroform as an eluent.

\section{Synthesis of esterified CA derivatives}

The partially and completely acetyl esterified CA derivatives were synthesized from CRA and $\mathrm{BCA}[\mathrm{n}](n=4,6,8)$ according to methods in literature, ${ }^{17-19}$ and named as CRA-Ex and BCA[n]-Ex, respectively, where $\mathrm{x}$ indicates the D.E. in percentage determined by ${ }^{1} \mathrm{H}$ NMR. The abbreviations and D.E.s of the corresponding esterified CA derivatives are as follows: CRA-E49 (D.E. $=48.6 \%$ ), CRA-E73 (D.E. $=73.4 \%)$, CRA-E100 (D.E. $=100 \%)$, BCA4-E50 (D.E. $=50 \%)$, BCA4-E100 (D.E. $=100 \%), \quad$ BCA6-E61 (D.E. $=60.8 \%)$, BCA6-E75 (D.E. $=$ $74.7 \%$ ), BCA6-E100 (D.E. $=100 \%$ ) and BCA8-E100 (D.E. $=100 \%)$. The molecular weight distributions $\left(M_{\mathrm{w}} / M_{\mathrm{n}}\right)$ of these derivatives were all in the range of 1.02-1.05. The synthesis and characterization of esterified CA derivatives were published elsewhere. ${ }^{20}$

\section{Model reactions of CA derivatives and GPE}

Model reactions of CA derivatives and GPE were carried out in a sealed glass tube at high temperature under vacuum. The corresponding reaction products were named CRA-Ex-GPE and BCA[n]-Ex-GPE, respectively. For example, the reaction product of CRA-E100 and GPE was named CRA-E100-GPE.

A typical procedure was as follows: CRA-E100 $(0.2202 \mathrm{~g}, 2 \mathrm{mmol}$ of ester groups), GPE ( $0.3004 \mathrm{~g}, 2 \mathrm{mmol}$, the ester group to epoxy group molar ratio was 1:1), TPPC ( $37.5 \mathrm{mg}, 0.1 \mathrm{mmol}, 5 \mathrm{~mol} \%$ of ester groups) and chlorobenzene $(0.5 \mathrm{ml}, 1 \mathrm{ml}$ of solvent for $1 \mathrm{~g}$ of raw material) were added to a glass tube. The glass tube was treated by four freeze-thaw cycles under reduced procedure and sealed by a gas torch. The reaction was performed with stirring at $120^{\circ} \mathrm{C}$ for $6 \mathrm{~h}$. After that, the reaction mixture was cooled to room temperature and directly used for ${ }^{1} \mathrm{H}$ NMR and gel permeation chromatography (GPC) measurements.

The addition reactions of other CA derivatives and GPE with a 1:1 molar ratio of ester groups and/or hydroxy groups to epoxy groups were carried out using TPPC as the catalyst in chlorobenzene under vacuum at $120^{\circ} \mathrm{C}$ for $6 \mathrm{~h}$ (Scheme 1). After the reactions were complete, the reaction mixtures were directly used for ${ }^{1} \mathrm{H}$ NMR and GPC measurements.

The chemical structure of the addition product was characterized by preparing CRA-E100-GPE in bulk using TPPC as the catalyst at $120^{\circ} \mathrm{C}$ for $6 \mathrm{~h}$, followed by a recycling preparative HPLC to isolate the product, and using the standard product for identification. ${ }^{1} \mathrm{H}$ NMR $\left(600 \mathrm{MHz}, \mathrm{CDCl}_{3}\right.$, tetramethylsilane, $\delta$, p.p.m.): 5.88-7.43 (m, 39.11H, aromatic $\mathrm{H}), 3.56-5.23(\mathrm{~m}$, $36.24 \mathrm{H},-\mathrm{CH}_{2}-$ and $\left.-\mathrm{CH}-\right), 1.84-2.28\left(\mathrm{~m}, 21.71 \mathrm{H}, \mathrm{CH}_{3} \mathrm{COO}-\right)$ and $1.38(\mathrm{~s}$, $\left.12 \mathrm{H}, \mathrm{CH}_{3}-\right)$. IR $\left(\mathrm{KBr}, \mathrm{cm}^{-1}\right): 2965,2926,2866(v \mathrm{C}-\mathrm{H}), 1742(v \mathrm{C}=\mathrm{O}$, ester $)$, 1599, 1497, 1456 ( $v$ aromatic $\mathrm{C}=\mathrm{C}), 1233(v \mathrm{C}-\mathrm{O}-\mathrm{C}$, ester and ether). GPC (tetrahydrofuran, polystyrene): $M_{\mathrm{n}}=1.49 \times 10^{3}, M_{\mathrm{w}} / M_{\mathrm{n}}=1.03$.

\section{RESULTS AND DISCUSSION}

\section{Characterization of product CRA-E100-GPE}

The addition reaction of CRA-E100 with GPE was carried out using TPPC as a bulk catalyst at $120^{\circ} \mathrm{C}$ for $6 \mathrm{~h}$. The product (CRA-E100GPE) was then separated by a recycling preparative HPLC. The chemical structure of the product was characterized by ${ }^{1} \mathrm{H}$ NMR, IR

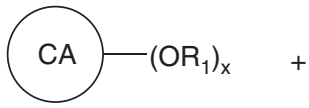

CA derivative

where, $x=4,6,8$

$\mathrm{R}_{1}=\mathrm{H},-\mathrm{COCH}_{3}$

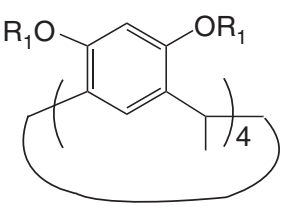

CRA,

CRA-E49,

CRA-E73,

CRA-E100

CRA derivatives

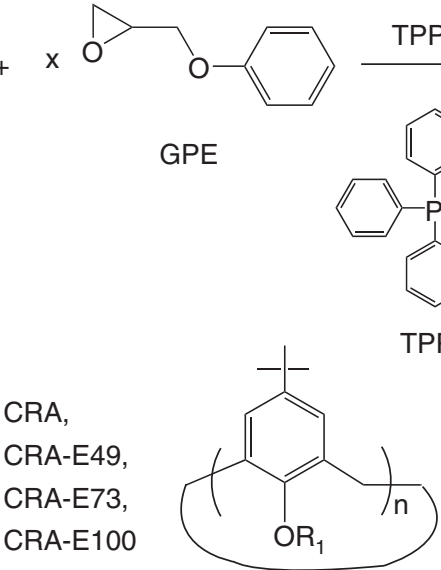

$\mathrm{BCA}[\mathrm{n}]$ derivatives

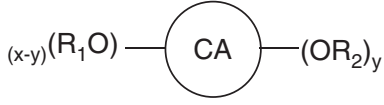

CA derivative-GPE

where, $0 \leq \mathrm{y} \leq \mathrm{x}$;

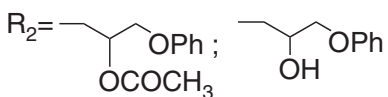

$\mathrm{n}=4 \quad \mathrm{n}=6 \quad \mathrm{n}=8$

BCA4, BCA6, BCA8,

BCA4-E50, BCA6-E61, BCA8-E100

BCA4-E100 BCA6-E75,

BCA6-E100

Scheme 1 Model reactions of calixarenes and their esterified derivatives with GPE. 
and GPC. Figure 1 shows GPC traces of isolated CRA-E100-GPE and the reaction mixture. The $M_{\mathrm{n}}$ and $M_{\mathrm{w}} / M_{\mathrm{n}}$ of the separated CRA-E100GPE were $1.49 \times 10^{3}$ and 1.03 , respectively. The molecular weight was much larger than that of the raw material CRA-E100 $\left(M_{\mathrm{n}}=0.75 \times 10^{3}\right)$. For IR spectra, the strong absorption peak at $1742 \mathrm{~cm}^{-1}$ could be assigned to the absorption of the carbonyl group. This represents a $19 \mathrm{~cm}^{-1}$ shift from the $1761 \mathrm{~cm}^{-1}$ peak of the raw material CRA-E100, suggesting that the aromatic carbonyl groups of CRA-E100 were successfully changed to the aliphatic carbonyl groups of CRA-E100GPE. Figure 2 showed the ${ }^{1} \mathrm{H}$ NMR spectrum of isolated CRA-E100GPE. The peaks at 5.88-7.43, 3.56-5.23, 1.84-2.28 and 1.38 p.p.m. could be assigned to aromatic protons, aliphatic protons, acetyl protons and methyl protons, respectively. The degree of introduction of GPE (D.I.) to CRA-E100 evaluated from aromatic protons and aliphatic protons in ${ }^{1} \mathrm{H}$ NMR using methyl protons as an internal standard were 78 and $80 \%$, respectively. This result demonstrates a successful reaction between the active ester groups of CRA-E100 and the epoxy groups of GPE. Therefore, esterified CA derivatives can function as curing agents for the thermal curing reactions of polyfunctional epoxy resins.

\section{Determination of D.I.}

Because a great deal of effort and time are required to isolate the product using a recycling preparative HPLC, a simple method should

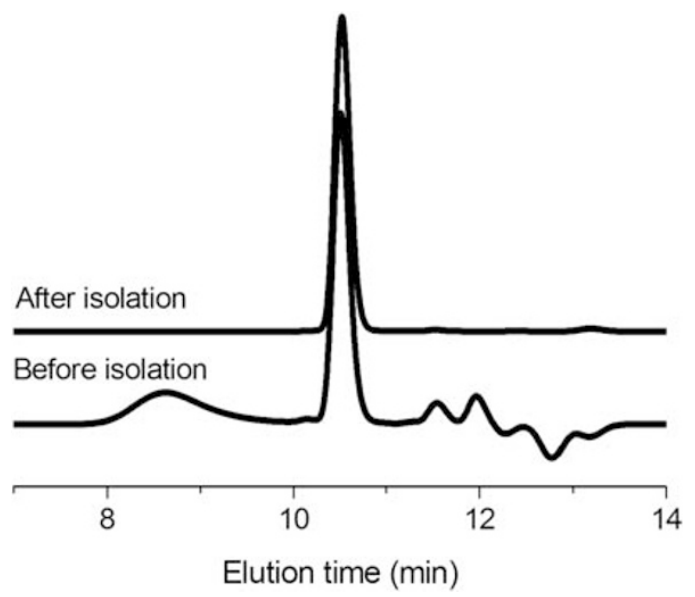

Figure 1 GPC traces of isolated CRA-E100-GPE and of the reaction mixture. be developed to determine the D.I. of model reactions without isolation. Inspired by Endo's work, ${ }^{21}$ we designed a method to determine D.I. by direct ${ }^{1} \mathrm{H}$ NMR and GPC measurements of reaction mixtures.

Figure 3 shows the ${ }^{1} \mathrm{H}$ NMR spectrum of the reaction mixture of CRA-E100 with GPE in chlorobenzene using TPPC as the catalyst (Run no. 12). Its GPC trace (shown later in Figure 6) had only one peak that was larger than that of the raw material CRA-E100, which suggested that all of the consumed GPE was incorporated into CRAE100. The peaks at $1.38(\mathrm{~s}, 12 \mathrm{H})$ and 2.76, $2.90(\mathrm{~d}, 0.35 \mathrm{H})$ p.p.m. in the ${ }^{1} \mathrm{H}$ NMR spectrum could be assigned to methyl protons of CRAE100-GPE and to methylene protons of the unreacted epoxy group (GPE), respectively. As the integral value of the methyl group in CRAE100 did not change after reaction, methyl protons could be used as an internal standard to determine the integral value of methylene protons of an epoxy group (GPE). Therefore, D.I. can be calculated according to the following formula:

$$
\text { D.I. }=\frac{\mathrm{GPE}_{\text {added }}-\mathrm{GPE}_{\text {residual }}}{\mathrm{GPE}_{\text {added }}} \times 100 \% \text {, }
$$

where $\mathrm{GPE}_{\text {added }}$ and $\mathrm{GPE}_{\text {residual }}$ represent the integral values of the methylene protons of epoxy groups in added and residual GPE, respectively, using methyl protons in CRA-E100 as an internal standard. For Run no. 12, as the added molar ratio of epoxy groups of GPE to ester groups of CRA-E100 was 1:1, GPE added was calculated to be $16 \mathrm{H}$ using the methyl protons $(12 \mathrm{H})$ of CRA-E100 as an internal standard. A GPE residual measurement of $0.35 \mathrm{H}$ by ${ }^{1} \mathrm{H}$ NMR corresponded to a D.I. of $98 \%$.

For the later addition reactions, when GPC traces indicated that no other side reactions occurred, all D.I.s were estimated using the above formula. Figure 4 plots the relationship between molecular weight and the D.I. of CRA-E100-GPE according to the experimental results (Run no.s $7,11,12,14,15,17,19$ and 20). These results demonstrate an almost linear increase in the molecular weight of CRA-E100-GPE with D.I., indicating that the above formula is credible.

\section{Optimization of reaction conditions}

The addition reaction of CRA-E100 with GPE was used to optimize reaction conditions such as catalyst, solvent, temperature and time.

Using five kinds of chemicals (4-dimethyl aminopyridine, triphenylphosphine, tetrabutylphosphonium bromide, tetraphenylphospho-

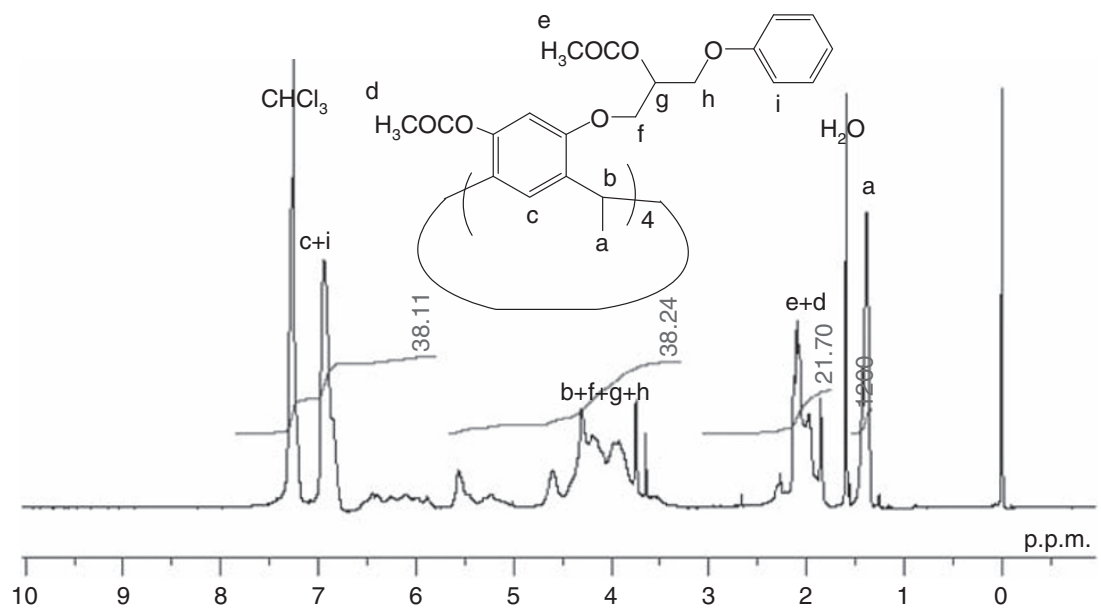

Figure $2{ }^{1} \mathrm{H}$ NMR spectrum of isolated CRA-E100-GPE $\left(\mathrm{CDCl}_{3}\right)$. 


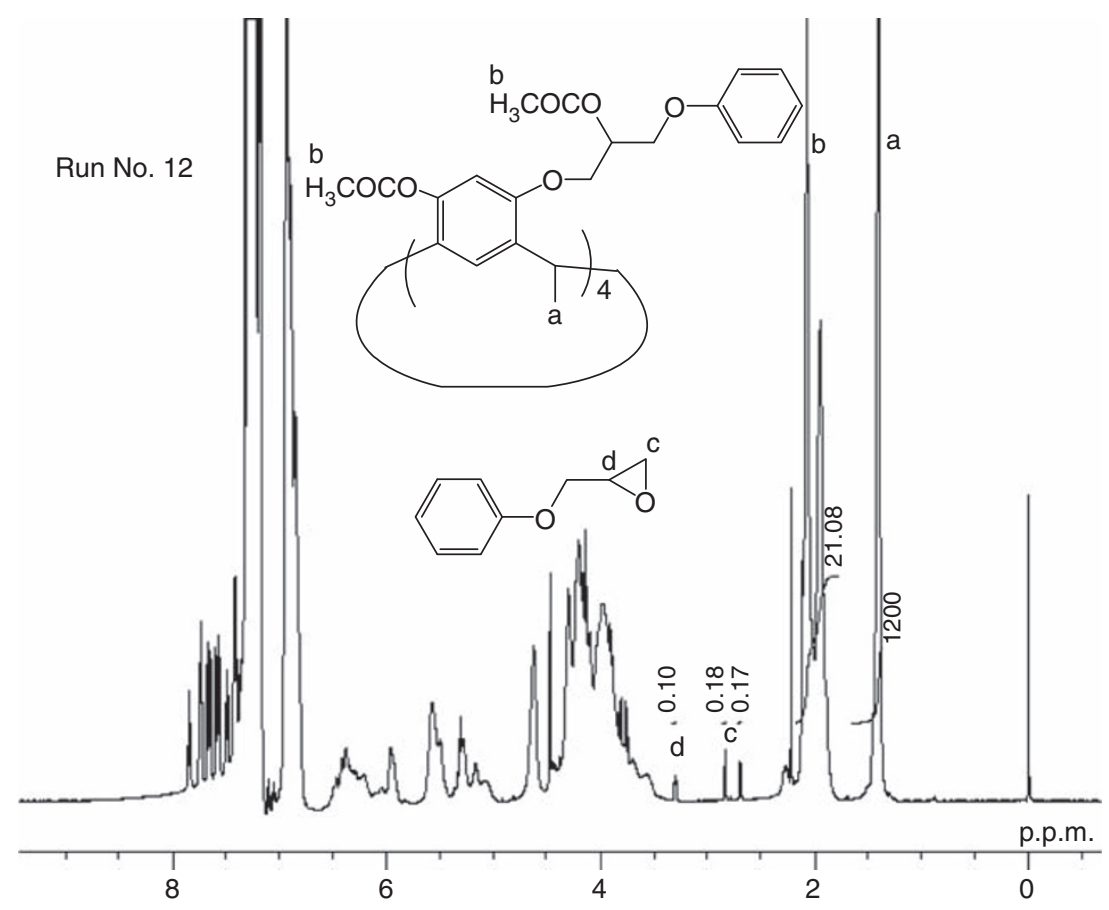

Figure $3{ }^{1} \mathrm{H}$ NMR spectrum of the reaction mixture of Run no. $12\left(\mathrm{CDCl}_{3}\right)$.

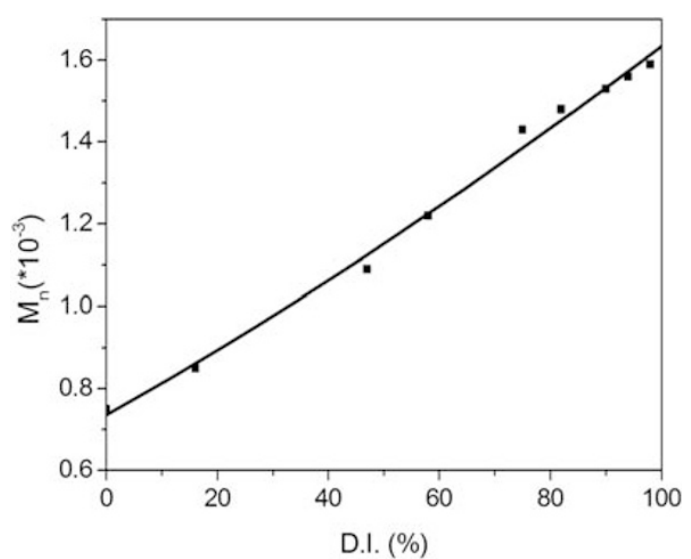

Figure 4 Relationship between the $M_{\mathrm{n}}$ and D.I. of CRA-E100-GPE.

nium bromide and TPPC) as catalysts, the reaction of CRA-E100 with GPE was carried out in bulk at $120^{\circ} \mathrm{C}$ for $6 \mathrm{~h}$. As the products were in the gel state, a small amount of $\mathrm{CDCl}_{3}$ was added to make them completely soluble. ${ }^{1} \mathrm{H}$ NMR and GPC were measured by using the above solution. Figure 5 shows that when the reaction was performed without a catalyst, the addition reaction between CRA-E100 and GPE did not occur, and the reaction occurred effectively with several different catalysts. However, except for triphenylphosphine, some side reactions also occurred. For the quaternary onium salts (tetrabutylphosphonium bromide, tetraphenylphosphonium bromide and TPPC), a peak at $2.9 \times 10^{4}$ appeared in addition to the peak at $1.50 \times 10^{3}$, and could be assigned to the self-polymerization of GPE. For 4-dimethyl aminopyridine, a shoulder peak at $4.9 \times 10^{3}$ was also observed, which could result from the side reaction of the subaliphatic hydroxyl group or of an acetoxy group of products with GPE.

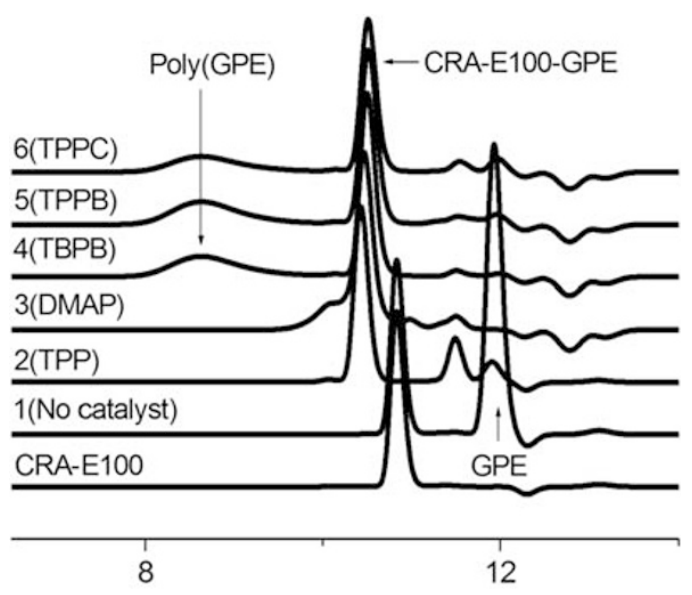

Elution time ( $\mathrm{min})$

Figure 5 GPC traces of the reaction mixtures of CRA-E100 and GPE using different catalysts in bulk.

Addition reactions were next performed in different solvents (chlorobenzene, anisole and $\mathrm{N}$-methyl-2-pyrrolidone) using the above catalysts at $120^{\circ} \mathrm{C}$ for $6 \mathrm{~h}$. After the reaction was complete, the homogeneous or heterogeneous reaction mixtures were used directly for ${ }^{1} \mathrm{H}$ NMR and GPC measurements. Table 1 summarizes the appearances, D.I.s and GPC results. The GPC traces (Figure 6) indicate that even for quaternary onium salts, only one peak larger than that of CRA-E100 was observed, which suggested that the selfpolymerization of GPE did not occur in solvent. Both chlorobenzene and $\mathrm{N}$-methyl-2-pyrrolidone are good solvents for the addition reaction of CRA-E100 with GPE. As the ${ }^{1} \mathrm{H}$ NMR spectrum of chlorobenzene does not overlap with that of GPE or the methyl group of CRA-E100, chlorobenzene was selected as the solvent for 
Table 1 Appearances, D.I.s and GPC results of the reaction mixtures of CRA-E100 and GPE using different combination of catalyst and solvent $^{\mathrm{a}}$

\begin{tabular}{llllcccc}
\hline & & & & & \multicolumn{2}{c}{$G^{2}$} \\
\cline { 5 - 7 } No. & Cat. & Solvent & Appearance & D.I. (\%) & $M_{n} \times 10^{-3}$ & $M_{W} / M_{n}$ \\
\hline 7 & TPP & Chlorobenzene & Heterogeneous & 16 & 0.85 & 1.04 \\
8 & TPP & NMP & Homogeneous & ND & 1.40 & 1.03 \\
9 & TPP & Anisole & Heterogeneous & 14 & 0.83 & 1.04 \\
10 & DMAP & Chlorobenzene & Homogeneous & 93 & 1.58 & 1.03 \\
11 & TPPB & Chlorobenzene & Heterogeneous & 75 & 1.43 & 1.03 \\
12 & TPPC & Chlorobenzene & Homogeneous & 98 & 1.59 & 1.03 \\
13 & TPPC & NMP & Homogeneous & ND & 1.37 & 1.03 \\
\hline
\end{tabular}

Abbreviations: DMAP, 4-dimethyl aminopyridine; GPC, gel permeation chromatography; GPE, glycidyl phenyl ether; ND, not determined; TPP, triphenylphospine; TPPB, tetrabutylphosphonium bromide; TPPC, tetraphenylphosphonium chloride.

aThe reactions were carried out by using different combination of catalyst and solvent at $120^{\circ} \mathrm{C}$ for $6 \mathrm{~h}$.

bD.I.: degree of introduction of GPE to CRA-E100, which was estimated by ${ }^{1} \mathrm{H}$ NMR.

${ }^{c} M_{\mathrm{n}}$ and $M_{\mathrm{w}} / M_{\mathrm{n}}$ were estimated by GPC in tetrahydrofuran using polystyrene as standard.

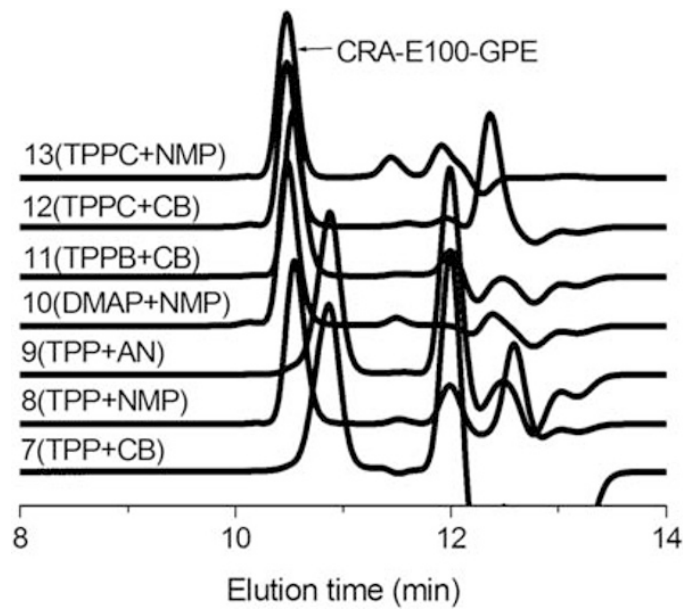

Figure 6 GPC traces of the reaction mixtures of CRA-E100 with GPE using different catalyst and solvent combinations (NMP: $N$-methyl-2-pyrrolidone, $\mathrm{CB}$ : chlorobenzene and AN: anisole).

further model reactions. When the reactions of CRA-E100 with GPE were carried out using different catalysts in chlorobenzene at $120^{\circ} \mathrm{C}$ for $6 \mathrm{~h}$, the D.I. order of products was triphenylphosphine $<$ tetraphenylphosphonium bromide $<4$-dimethyl aminopyridine $<$ TPPC, meaning that the combination of chlorobenzene and TPPC showed the best reactivity. Therefore, chlorobenzene and TPPC were selected as the solvent and catalyst for later reactions.

To study the effect of temperature, the model reactions of CRAE100 with GPE were performed using TPPC as the catalyst in chlorobenzene for $2 \mathrm{~h}$ at $90,100,110,120$ and $130^{\circ} \mathrm{C}$. The reaction mixtures were homogeneous at all temperatures. Table 2 summarizes the appearances, D.I.s and GPC results. Both the $M_{\mathrm{n}}$ and D.I. values of CRA-E100-GPE were lower when the reaction temperature was below $100^{\circ} \mathrm{C}$. When the reaction temperature was higher than $110^{\circ} \mathrm{C}$, both $M_{\mathrm{n}}$ and D.I. of CRA-E100-GPE increased, which meant that the addition reaction showed high reactivity over $110^{\circ} \mathrm{C}$. However, when the reaction temperature was increased to $130^{\circ} \mathrm{C}$, both the $M_{\mathrm{n}}$ and D.I. of CRA-E100-GPE remained almost constant. Thus, the low threshold temperature for the addition reaction of CRA-E100 with GPE was $110^{\circ} \mathrm{C}$.
Table 2 Appearances, D.I.s, and GPC results of the reaction mixtures of CRA-E100 with GPE at different reaction temperature ${ }^{a}$

\begin{tabular}{|c|c|c|c|c|c|}
\hline \multirow[b]{2}{*}{ No. } & \multirow[b]{2}{*}{ Temp. $\left.{ }^{\circ} \mathrm{C}\right)$} & \multirow[b]{2}{*}{ Appearance } & \multirow[b]{2}{*}{ D.I. $(\%)^{\mathrm{b}}$} & \multicolumn{2}{|c|}{$G P C^{c}$} \\
\hline & & & & $M_{n} \times 10^{-3}$ & $M_{W} / M_{n}$ \\
\hline 14 & 90 & Homogeneous & 47 & 1.09 & 1.03 \\
\hline 15 & 100 & Homogeneous & 58 & 1.22 & 1.04 \\
\hline 16 & 110 & Homogeneous & 94 & 1.56 & 1.03 \\
\hline 17 & 120 & Homogeneous & 94 & 1.56 & 1.03 \\
\hline 18 & 130 & Homogeneous & 94 & 1.55 & 1.03 \\
\hline
\end{tabular}

Abbreviations: GPC, gel permeation chromatography; GPE, glycidyl phenyl ether; Temp., temperature; TPPC, tetraphenylphosphonium chloride.

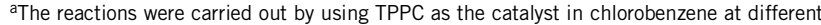
temperature for $2 \mathrm{~h}$.

${ }^{\text {bD } D . I .: ~ d e g r e e ~ o f ~ i n t r o d u c t i o n ~ o f ~ G P E ~ t o ~ C R A-E 100, ~ w h i c h ~ w a s ~ e s t i m a t e d ~ b y ~}{ }^{1} \mathrm{H}$ NMR.

${ }^{c} M_{\mathrm{n}}$ and $M_{\mathrm{w}} / M_{\mathrm{n}}$ were estimated by GPC in tetrahydrofuran using polystyrene as standard.

Table 3 Appearances, D.I.s, and GPC results of the addition reactions of CRA-E100 with GPE for different reaction time ${ }^{a}$

\begin{tabular}{|c|c|c|c|c|c|}
\hline \multirow[b]{2}{*}{ No. } & \multirow[b]{2}{*}{ Time (h) } & \multirow[b]{2}{*}{ Appearance } & \multirow[b]{2}{*}{ D.I. $(\%)^{\mathrm{b}}$} & \multicolumn{2}{|c|}{$G P C^{c}$} \\
\hline & & & & $M_{n} \times 10^{-3}$ & $M_{W} / M_{n}$ \\
\hline 19 & 0.25 & Homogeneous & 82 & 1.48 & 1.03 \\
\hline 20 & 0.5 & Homogeneous & 90 & 1.53 & 1.03 \\
\hline 21 & 1 & Homogeneous & 93 & 1.54 & 1.03 \\
\hline 17 & 2 & Homogeneous & 94 & 1.56 & 1.03 \\
\hline 12 & 6 & Homogeneous & 98 & 1.59 & 1.03 \\
\hline 22 & 9 & Homogeneous & 98 & 1.58 & 1.03 \\
\hline
\end{tabular}

Abbreviations: GPC, gel permeation chromatography; GPE, glycidyl phenyl ether; TPPC, tetraphenylphosphonium chloride.

the reactions were caried out by using TPPC as the catalyst in chlorobenzene at $120^{\circ} \mathrm{C}$ for aThe reactions were carried out by using TPPC as the catalyst in chlorobenzene at $120^{\circ} \mathrm{C}$ for different time.

${ }^{b}$ D.I.: degree of introduction of GPE to CRA-E100, which was estimated by ${ }^{1} \mathrm{H}$ NMR

${ }^{C} M_{\mathrm{n}}$ and $M_{\mathrm{w}} / M_{\mathrm{n}}$ were estimated by GPC in tetrahydrofuran using polystyrene as standard.

To study the effect of time, the model reactions of CRA-E100 with GPE were examined using TPPC as the catalyst in chlorobenzene at $120^{\circ} \mathrm{C}$ for $0.25,0.5,1,2,6$ and $9 \mathrm{~h}$. The reaction mixture became homogeneous within $15 \mathrm{~min}$. Table 3 summarizes the appearances, D.I.s and GPC results. The D.I.s of CRA-E100-GPE after 15 and 30 min were 82 and $90 \%$, respectively. This indicates that the reaction of CRA-E100 with GPE proceeded quickly under the above reaction conditions. D.I. increased up to $98 \%$ when the time was prolonged to $6 \mathrm{~h}$, but remained almost constant when time was further prolonged to $9 \mathrm{~h}$. These results indicate that the reaction of CRA-E100 with GPE could reach a reaction balance within $6 \mathrm{~h}$.

According to the effects of catalyst, solvent, temperature and time on the reaction of CRA-E100 with GPE, the optimum reaction conditions for the model reaction were determined to be TPPC catalyst in chlorobenzene at $120^{\circ} \mathrm{C}$ for $6 \mathrm{~h}$.

\section{Possible reaction mechanisms}

The reaction mechanisms of CRA-E100 and GPE using TPPC as the catalyst can be considered according to the previously proposed mechanism by our research group for the reaction of epoxy compounds with carboxylic acid esters ${ }^{22}$ or diphenyl carbonate, ${ }^{23}$ using quaternary onium salts $\left(\mathrm{Q}^{+} \mathrm{X}^{-}\right)$as catalysts. As shown in Scheme 2, the counteranion of the catalyst in this system interacts with the $\beta$-carbon of the epoxy group of GPE to provide an activated GPE. The activated GPE then reacts with the ester group of CRA-E100 to form 
<smiles>[X]CC1(CO)O[C@@H]1COc1ccccc1</smiles>

GPE

Activated GPE

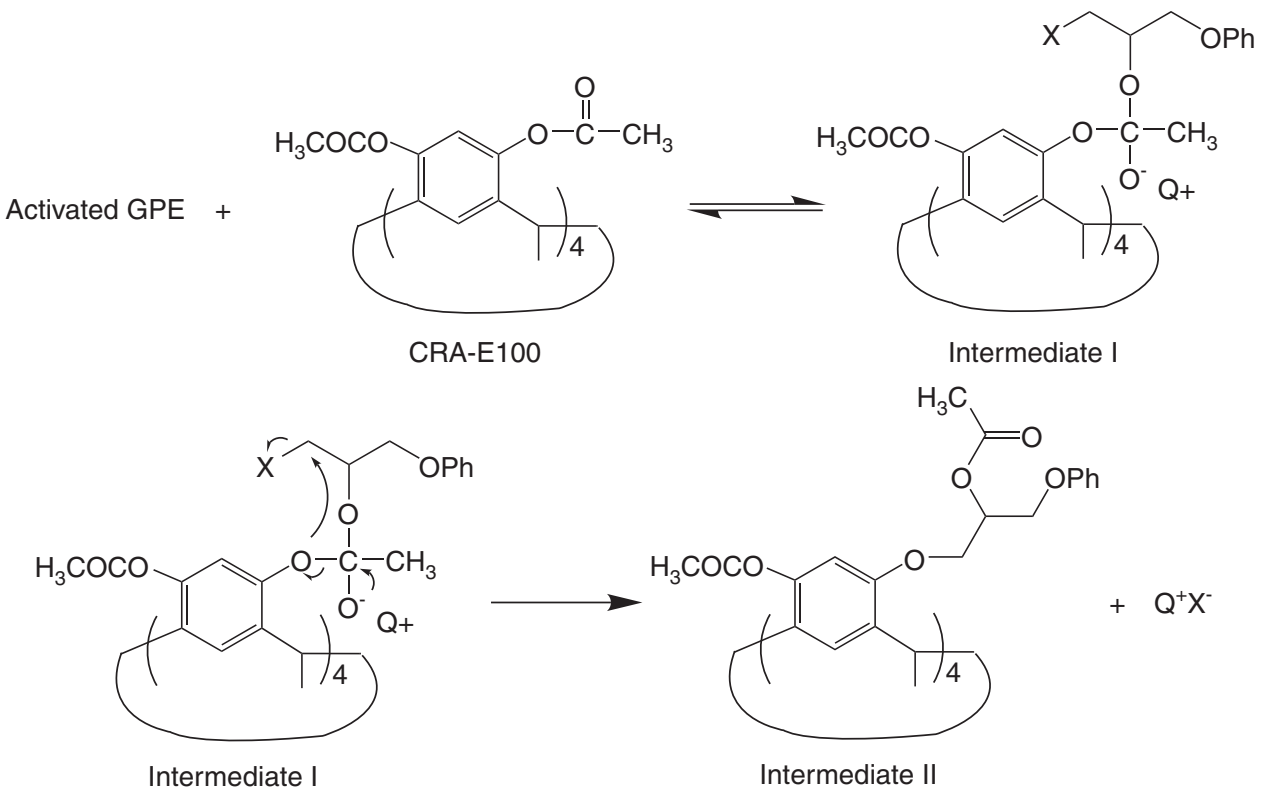

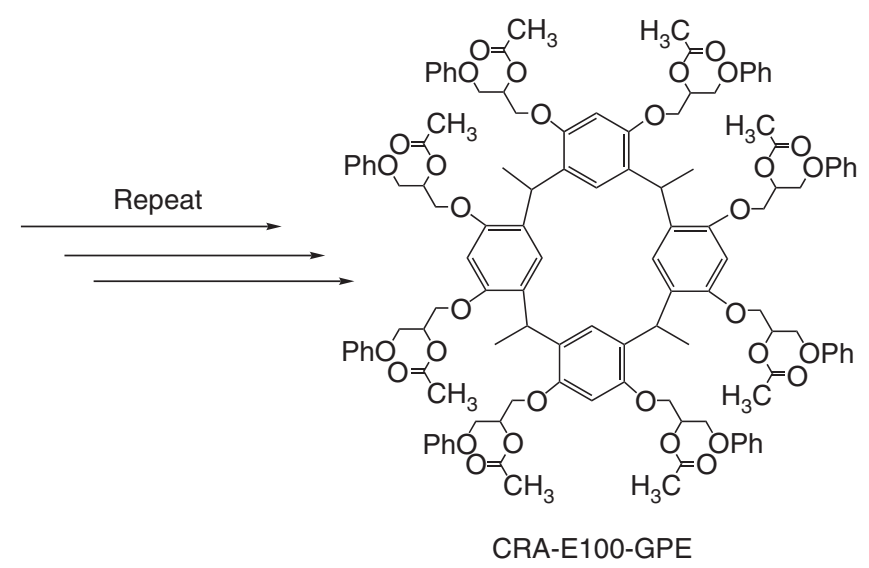

Scheme 2 Possible reaction mechanism of CRA-E100 and GPE using $Q^{+} X^{-}($TPPC) as a catalyst.

tetrahedral intermediate I. Thereafter, intermediate I is transformed to produce intermediate II, releasing the catalyst. Repetition of the above steps leads to the formation of CRA-E100-GPE.

\section{Comparison of the reactivity of various CAs and their esterified derivatives with GPE}

As shown in Scheme 1, the addition reaction of CAs and their esterified derivatives with GPE was performed under the above optimized reaction conditions and at a 1:1 molar ratio of ester groups and/or hydroxy groups to epoxy groups. After the reaction was completed, the reaction mixture was directly used for ${ }^{1} \mathrm{H}$ NMR and GPC measurements. Table 4 summarizes the appearances, D.I.s and GPC results of the above reactions.

Under the above reaction conditions, the reaction mixtures of CRA and its esterified derivatives with GPE became homogeneous in a few minutes. All D.I.s were greater than $95 \%$, and no self-polymerization of GPE occurred. These results demonstrate that both hydroxy groups and ester groups of CRA derivatives have high reactivity with the epoxy groups of GPE. Therefore, CRA and its esterified derivatives are good potential curing agents for epoxy resins.

For the reactions of $\mathrm{BCA}[\mathrm{n}](n=4,6,8)$ and their esterified derivatives with GPE, most of the reaction mixtures were heterogeneous. Reaction mixtures of BCA6 and BCA8 could not be completely dissolved in $\mathrm{CDCl}_{3}$, dimethylsulfoxide- $\mathrm{d}_{6}$, tetrahydrofuran or dimethyl formamide, hence their D.I.s and molecular weights were not measured. The low reactivity of $\mathrm{BCA}[\mathrm{n}](n=4,6,8)$ with epoxy groups may result from the existence of strong intermolecular hydrogen bonding in $\mathrm{BCA}[\mathrm{n}](n=4,6,8)$ molecules. Because the hydroxy groups of CRA are located extra-annularly on the upper rim and those of $\mathrm{BCA}[\mathrm{n}](n=4,6,8)$ are located intra-annularly on the lower rim, the intermolecular hydrogen bonding in $\mathrm{BCA}[\mathrm{n}](n=4,6,8)$ is much stronger than that in CRA. Therefore, although the reaction of CRA with GPE could proceed quickly at $120^{\circ} \mathrm{C}$, the temperature may still be lower than the threshold temperature for the reactions of BCA[n] 
Table 4 Appearances, D.I.s, and GPC results of the reaction mixtures of various $\mathrm{CA}$ and their esterified derivatives with $\mathrm{GPE}^{\mathrm{a}}$

\begin{tabular}{|c|c|c|c|c|c|}
\hline \multirow[b]{2}{*}{ No. } & \multirow[b]{2}{*}{ CA derivatives } & \multirow[b]{2}{*}{ Appearance } & \multirow[b]{2}{*}{ D.I. $(\%)^{b}$} & \multicolumn{2}{|c|}{$G P C^{c}$} \\
\hline & & & & $M_{n} \times 10^{-3}$ & $M_{W} / M_{n}$ \\
\hline 23 & CRA & Homogeneous & 96 & 1.56 & 1.03 \\
\hline \multirow[t]{2}{*}{24} & CRA-E49 & Homogeneous & 96 & 1.60 & 1.03 \\
\hline & CRA-E49 & & & 0.67 & 1.04 \\
\hline \multirow[t]{2}{*}{25} & CRA-E73 & Homogeneous & 95 & 1.54 & 1.03 \\
\hline & CRA-E73 & & & 0.72 & 1.03 \\
\hline \multirow[t]{2}{*}{12} & CRA-E100 & Homogeneous & 98 & 1.59 & 1.03 \\
\hline & CRA-E100 & & & 0.75 & 1.03 \\
\hline 26 & BCA4 & Homogeneous & 44 & 0.83 & 1.02 \\
\hline \multirow[t]{2}{*}{27} & BCA4-E50 & Homogeneous & 67 & 0.90 & 1.03 \\
\hline & BCA4-E50 & & & 0.62 & 1.03 \\
\hline \multirow[t]{2}{*}{28} & BCA4-E100 & Heterogeneous & 50 & 0.84 & 1.05 \\
\hline & BCA4-E100 & & & 0.66 & 1.03 \\
\hline 29 & BCA6 & Heterogeneous & ND & ND & ND \\
\hline \multirow[t]{2}{*}{30} & BCA6-E61 & Homogeneous & 81 & 1.39 & 1.03 \\
\hline & BCA6-E61 & & & 0.91 & 1.03 \\
\hline \multirow[t]{2}{*}{31} & BCA6-E75 & Homogeneous & 69 & 1.33 & 1.03 \\
\hline & BCA6-E75 & & & 0.92 & 1.03 \\
\hline \multirow[t]{2}{*}{32} & BCA6-E100 & Heterogeneous & 68 & 1.32 & 1.03 \\
\hline & BCA6-E100 & & & 0.93 & 1.03 \\
\hline 33 & BCA8 & Heterogeneous & ND & ND & ND \\
\hline \multirow[t]{2}{*}{34} & BCA8-E100 & Heterogeneous & 72 & 1.73 & 1.03 \\
\hline & BCA8-E100 & & & 1.24 & 1.02 \\
\hline
\end{tabular}

Abbreviations: CA, calixarene; GPC, gel permeation chromatography; GPE, glycidyl phenyl ether; ND, not determined; Temp., temperature; TPPC, tetraphenylphosphonium chloride.

aThe reactions were carried out by using TPPC as the catalyst in chlorobenzene at $120^{\circ} \mathrm{C}$ for $6 \mathrm{~h}$. ${ }^{b}$ D.I.: degree of introduction of GPE to CA derivatives, which was estimated by ${ }^{1} \mathrm{H}$ NMR.

${ }^{c} M_{\mathrm{n}}$ and $M_{\mathrm{w}} / M_{\mathrm{n}}$ were estimated by GPC in tetrahydrofuran using polystyrene as standard.

$(n=4,6,8)$ with GPE. That is to say, when using BCA[n] $(n=4,6,8)$ as curing agents for epoxy resins, the reaction temperature should be further increased to activate the hydroxy groups.

Meanwhile, as the ester groups of $\mathrm{BCA}[\mathrm{n}]-\mathrm{E} 100(n=4,6,8)$ increased their solubility, the reaction mixtures of BCA[n]-E100 $(n=4,6,8)$ and GPE were completely soluble in $\mathrm{CDCl}_{3}$ and tetrahydrofuran. Their GPC traces indicated that no self-polymerization of GPE occurred. Using the tert-butyl group $\left(-\mathrm{C}\left(\mathrm{CH}_{3}\right)_{3}\right)$ of BCA[n]E100 $(n=4,6,8)$ as an internal standard, the integral value of unreacted GPE (GPE $\left.\mathrm{G}_{\text {residual }}\right)$ could be estimated. According to the former formula, the D.I.s for the reactions of BCA4-E100, BCA6-E100 and BCA6-E100 with GPE were calculated as 50, 68 and 72\%, respectively. All of these D.I.s were much lower than the $98 \%$ D.I. of the reaction of CRA-E100 with GPE, indicating that the reactivity of ester groups in BCA[n]-E100 $(n=4,6,8)$ with GPE was much poorer than that of ester groups in CRA-E100 with GPE, perhaps because of steric hindrance. As shown in Scheme 2, after the addition reaction of ester groups with GPE, the substituent group became bulky, and the bulky substituent group will affect the later formation of an intermediate of CA-GPE with activated GPE. As the functional groups of CRA-E100 are placed extra-annularly on the upper rim and have almost no effect on the formation of the later intermediate, the reaction was able to proceed quickly and reached a very high D.I. While the functional groups of BCA[n]-E100 $(n=4,6,8)$ are placed intra-annularly on the lower rim, the bulky substituent group will greatly increase steric hindrance and hinder the formation of the later intermediate, leading to a reaction balance at low D.I. Furthermore, the D.I. of BCA6-E100-GPE is similar to that of BCA8-E100-GPE and larger than that of BCA4-E100-GPE, again possibly because of steric hindrance. As the ring of BCA4-E100 is smaller than those of BCA6-E100 and BCA8-E100, the reaction balance of BCA4-E100 and activated GPE was reached at a lower D.I than for the reaction of BCA6-E100 or BCA8-E100 with activated GPE.

\section{CONCLUSIONS}

With the goal of using CA derivatives as curing agents for polyfunctional epoxy resins, this study examined model reactions of CAs and their esterified derivatives with the monofunctional epoxy compound GPE. The results of these studies lead to the following conclusions:

1. Direct ${ }^{1} \mathrm{H}$ NMR and GPC measurements of the reaction mixture enabled simple determination of D.I.

2. According to the effects of catalyst, solvent, temperature and time on the reaction of CRA-E100 and GPE, the optimum reaction conditions were determined to be TPPC catalyst in chlorobenzene at $120^{\circ} \mathrm{C}$ for $6 \mathrm{~h}$.

3. The addition reactions of CAs and their esterified derivatives with GPE were performed under the above optimized reaction conditions and at a 1:1 molar ratio of ester groups and/or hydroxy groups to epoxy groups. The reactions of CRA and its esterified derivatives with GPE proceeded quickly, and D.I.s were higher than $95 \%$. For BCA $[\mathrm{n}](n=4,6,8)$ and their esterified derivatives, the reaction mixtures were almost heterogeneous, and D.I.s were lower than $81 \%$.

4. The difference in the reactivities of CA derivatives with GPE resulted from differences in their intermolecular hydrogen bonding and steric hindrance.

5. CRA derivatives have great potential as curing agents for polyfunctional epoxy resins. BCA8 derivatives and BCA6 derivatives can be used as curing agents for polyfunctional epoxy resins, but BCA4 derivatives are not suitable for this application.

\section{CONFLICT OF INTEREST}

The authors declare no conflict of interest.

1 Ikeda, A. \& Shinkai, S. Novel cavity design using calix[n]arene skeletons: toward molecular recognition and metal binding. Chem. Rev. 97, 1713-1734 (1997).

2 Sliwa, W. \& Deska, M. Calixarene complexes with soft metal ions. ARKIVOC i, 87-127 (2008).

3 Jose, P. \& Menon, S. Lower-rim substituted calixarenes and their applications. Bioinorg. Chem. Appl. 65815 (2007) (doi:10.1155/2007/65815) http://www.ncbi.nlm.nih.gov/ pmc/articles/PMC1885865/pdf/BCA2007-65815.pdf.

4 Nishikubo, T., Kameyama, A., Tsutsui, K. \& Iyo, M. Synthesis and photochemical reaction of novel $\mathrm{p}$-alkylcalix[n]arene derivatives containing cationically polymerizable groups. J. Polym. Sci., Part A: Polym. Chem. 37, 1805-1814 (1999).

5 Nishikubo, T., Kameyama, A. \& Tsutsui, K. Synthesis of photoreactive calixarene derivatives containing pendant cyclic ether groups. J. Polym. Sci., Part A: Polym. Chem. 39, 1169-1179 (2001).

6 Nishikubo, T., Kameyama, A., Kudo, H. \& Tsutsui, K. Synthesis and photochemical reaction of cyclic oligomers: synthesis and photopolymerization of novel C-methylcalix[4]resorcinarene and p-alkylcalix[n]arene derivatives containing spiro ortho ether groups. J. Polym. Sci., Part A: Polym. Chem. 40, 1293-1302 (2002).

7 Kudo, H., Mitani, K., Nishikubo, T., Mitsuishi, M. \& Miyashita, T. The Synthesis and photo-induced deprotection reaction of calix[4]resorcinarene derivatives containing t-butyl ester moieties. Bull. Chem. Soc. Jpn. 77, 819-826 (2004).

8 Ren, H., Sun, J. Z., Zhao, Q., Zhou, Q. Y. \& Ling, Q. C. Synthesis and characterization of a novel heat resistant epoxy resin based on N, N'-bis(5-hydroxy-1-naphthyl)pyromellitic diimide. Polymer 49, 5249-5253 (2008).

9 Sharma, P., Choudhary, V. \& Narula, A. K. Effect of structure of aromatic imide-amines on curing behavior and thermal stability of diglycidyl ether of bisphenol-A. J. Appl. Polym. Sci. 107, 1946-1953 (2008).

10 Ho, T. H., Hwang, H. J., Shieh, J. Y. \& Chung, M. C. Thermal, physical and flameretardant properties of phosphorus-containing epoxy cured with cyanate ester. React. Funct. Polym. 69, 176-182 (2009).

$11 \mathrm{Ho}, \mathrm{T}$. H. Synthesis of naphthalene containing aralkyl novolac epoxy resins for electronic application. Macromol. Mater. Eng. 283, 57-61 (2000). 
12 Nishikubo, T. \& Tanaka, K. A novel reaction of epoxy resins with polyfunctional active esters. J. Appl. Polym. Sci. 33, 2821-2831 (1987).

13 Nakamura, S., Saegusa, Y., Yanagasawa, H., Touse, M., Shirai, T. \& Nishikubo, T. Thermal analysis of epoxy curing using polyfunctional active esters as curing agents. Thermochim. Acta 183, 269-277 (1991).

14 Ito, N., Tonosaki, S., Kudo, H., Kameyama, A. \& Nishikubo, T. Synthesis and characterization of fluoropolymers by the polyaddition of bis(epoxide)s with dicarboxylic acids and diols. J. Polym. Sci., Part A: Polym. Chem. 40, 1395-1404 (2002).

15 Nishikubo, T., Kameyama, A. \& Yaguchi, T. Synthesis of poly(cyanurate)s by a novel polyaddition of bis(epoxide)s with triazine dichloride. J. Polym. Sci., Part A: Polym. Chem. 38, 4006-4012 (2000).

16 Nishikubo, T., Kameyama, A. \& Sayito, C. A novel polyaddition of bis(epoxide)s with triazine diaryl ether for the synthesis of poly(ether)s containing triazine group in the main chain. J. Polym. Sci., Part A: Polym. Chem. 38, 3604-3611 (2000).

17 Ito, H., Nakayama, T., Sherwood, M., Miller, D. \& Ueda, M. Characterization and lithographic application of calix[4]resorcinarene derivatives. Chem. Mater. 20, 341-356 (2008).
18 Hogberg, A. G. S. Two stereoisomeric macrocyclic resorcinol-acetaldehyde condensation products. J. Org. Chem. 45, 4498-4500 (1980).

19 Jaime, C., Mendoza, J. D., Prados, P., Nieto, P. M. \& Sanchez, C. Carbon-13 NMR chemical shifts. A single rule to determine the conformation of calix[4]arenes. J. Org. Chem. 56, 3372-3376 (1991).

20 Xu, S. G., Kudo, H., Nishikubo, T., Nakamura, S. \& Numata, S. Thermal cured epoxy resins using certain calixarenes and their esterified derivatives as curing agents. J. Poly. Sci. Part A: Poly. Chem. 48, 1931-1942 (2010).

21 Shimomura, O., Tomita, I. \& Endo, T. Cationic polymerization of glycidyl phenyl ether initiated by sulfonium salts of phenoxathiin and thianthrene as novel thermal latent cationic initiators. J. Polym. Sci., Part A: Polym. Chem. 37, 127-128 (1999).

22 Nishikubo, T. \& Kameyama, A. Addition-reactions of cyclic ethers with various carbonyl-compounds and their application for polymer synthesis. Prog. Polym. Sci. 18, 963-995 (1993).

23 Yashiro, T., Matsushima, K., Kameyama, A. \& Nishikubo, T. A novel synthesis of poly(carbonate)s by the polyaddition of bis(epoxide)s with diphenyl carbonate. Macromolecules 34, 3205-3210 (2001). 